Удк $635.7: 663.14 .036$

\title{
ВІТРЯК Оксана,
}

к. т. н., доцент кафедри технологї і організациї

ресторанного господарства Київсъкого національного

торговельно-економічного університету

\section{ТКАЧЕНКО Любов,}

к. т. н., доцент кафедри технологї $і$ організацї

ресторанного господарства Київсъкого національного

торговельно-економічного університету

\section{ПРИБИЛЬСБКИЙ Віталій,}

д. т. н., професор кафедри біотехнологї̈ продуктів бродіння

і виноробства Національного університету харчових технологій

\section{ТЕХНОАОГІЯ ФЕРМЕНТОВАНИХ НАПОЇВ HA OCHOBI MEDUSOMYCES GISEVII $V$ З ПРЯНО-АРОМАТИЧНОЮ СИРОВИНОЮ}

Досліджено й науково обтрунтовано доцільність використання в технології ферментованих напої на основі культури мікроорганізмів Medusomyces gisevii $V$ пряно-ароматичної сировини, багатої на біологічно активні речовини. Вивчено вплив на тривалість бродіння та органолептичні властивості готового напою водних екстрактів м'яти, меліси, лофанту й солодки. Встановлено технологічні параметри приготування ферментованих напоїв на основі культури мікроорганізмів Medusoтусеs gisevii Vз використанням раціональної кількості зазначених водних екстрактів.

Ключові слова: ферментовані напої, культура мікроорганізмів Medusomyces gisevii $V$, пряно-ароматична сировина, м’ята, меліса, лофант, солодка.

(C) Вітряк Оксана, Ткаченко Любов, Прибильський Віталій, 2018 
Витряк О., Ткаченко Л., Прибыльский В. Технология ферментированных напитков на основе Medusomyces gisevii $V$ с пряно-ароматическим сырьем. Исследована и научно обоснована целесообразность использования в технологии ферментированных напитков на основе культуры микроорганизмов Medusoтусеs gisevii V пряно-ароматического сырья, богатого биологически активными веществами. Изучено влияние на продолжительность брожения и органолептические свойства готового напитка водных экстрактов мяты, мелиссы, лофанта и солодки. Определены технологические параметры приготовления ферментированных напитков на основе культуры микроорганизмов Medusomyces gisevii $V$ с использованием раиионального количества указанных водных экстрактов.

Ключевые слова: ферментированные напитки, культура микроорганизмов Medusomyces gisevii V, пряно-ароматическое сырье, мята, мелисса, лофант, солодка.

Постановка проблеми. Здавна відомі напої домашнього приготування, серед яких особливо поширеними є хлібний квас, чайний гриб, рисовий гриб, кефірний гриб, ферментовані на основі сорго та ін. Ці напої відрізняються своєю основою, складом закваски та смаком. Об'єднує їх те, що вони є ферментованими, тобто напоями бродіння, які відносяться до натуральних продуктів функціонального призначення, здатних підвищувати загальний стан здоров'я людини та поліпшувати діяльність організму. Технологія таких напоїв базується на використанні натуральної сировини та мікроорганізмів визначеного складу. При їх життєдіяльності утворюється комплекс цінних і корисних для організму людини біологічно активних речовин, зокрема органічні кислоти, амінокислоти, вітаміни, ферменти тощо [1-3].

В Україні та світі популярним $є$ ферментований напій із тривіальною назвою "чайний гриб" ("чайний квас", "комбуха", "комбуча" тощо), при приготуванні якого чайно-цукровий розчин зброджують симбіотичною полікультурою мікроорганізмів Medusomyces gisevii, яка містить дріжджі та оцтовокислі бактерії. Останні під час життєдіяльності продукують органічні кислоти (оцтову, молочну, глюконову, койєву), вітаміни С, групи В, амінокислоти, ферменти та інші біологічно активні сполуки. Унаслідок бродіння отримують приємний, природно газований, освіжаючий напій з кисло-солодким смаком [1].

Напій на основі культури Medusomyces gisevii, крім приємних органолептичних характеристик, має широку фармацевтичну дію. Народна медицина рекомендує його застосовувати при шлунково-кишкових захворюваннях, для регулювання артеріального тиску, рівня холестерину. Напій корисний при порушеннях обміну речовин в організмі, підвищеному вмісту цукру в крові. Як протизапальний засіб його вживають при застудах, гострому запаленні верхніх дихальних шляхів, гострих формах ангіни, хронічному тонзиліті. Численні клінічні дослідження, проведені в РФ [2], Казахстані [4], Німеччині [5], підтверджують лікувальні властивості цього напою.

Україна багата на рослинну дикорослу сировину, зокрема пряноароматичну, що містить велику кількість біологічно активних речовин. 
Такі рослини характеризуються високим вмістом ефірних олій, що уможливлює отримати "фітонапої з багатогранними смаковими характеристиками" [6-8].

Аналіз останніх досліджень і публікацій. Науковці України приділяли достатню увагу дослідженням щодо можливості використання пряно-ароматичної сировини (ПАС) в технології різних груп напоїв. Додавання до пивних напоїв екстрактів із трави меліси, листя підбілу, трави чебрецю і звіробою не лише підвищило стабільність смаку готового напою, а й позитивно вплинуло на збереження в ньому гірких речовин хмелю. Включення до охмеленого сусла гвоздики, коріандру, м'яти сприяло підвищенню колоїдної стійкості готового пива та покращувало їхні органолептичні властивості [9]. Досліджено використання пряноароматичної сировини Закарпаття (фенхель, лофант, чабер гірський, лаванда, м'ята перцева, гісоп, чабер запашний, меліса, материнка) в технології вермутів, що сприяло розширенню асортименту та надання напоям оригінального смаку [6;8].

Відомі дослідження науковців інших країн щодо використання екстрактів меліси та орегано в безалкогольних напоях на основі концентрату чайного гриба: "Мелісовий" (Б. Н. Огарков зі співавторами, РФ) [10] i "Чайний квас з материнкою" (Б. К. Жумабекова, К. А. Жумабекова, Казахстан) [11].

Наразі залишається актуальним дослідження щодо розширення асортименту ферментованих напоїв з використанням вітчизняної ПАС.

Мета роботи - наукове обгрунтування використання пряноароматичної сировини в технології ферментованого напою на основі культури мікроорганізмів Medusomyces gisevii для інтенсифікації технологічного процесу та покращення органолептичних властивостей.

Матеріали та методи. Використано консорціум мікроорганізмів Medusomyces gisevii $V$, до складу якого входили дріжджі Zygosaccharomyces fermentati $V$ і оцтовокислі бактерії - Acetobacter xylinum $V$ у співвідношенні в середньому 1:100 [12].

Сировина для приготування напою: питна вода 3 київського водогону за ДСанПіН 2.2.4-171-10 [13] та ДСТУ 7525:2014 [14]; цукор білий за ДСТУ 4623-2006 [15] у вигляді цукрового сиропу; листя чаю чорного байхового фасованого за ДСТУ 7174:2010 [16]; лікарські та пряно-ароматичні рослини: сухий екстракт 3 листя м'яти перцевої та меліси лимонної, лофант анісовий за ДФУ-2018 [17], корінь солодки за ГОСТ 22839-88 [18].

Сусло підготовлено за технологічною схемою (рисунок). Воду прокип'ячено з метою знезараження, зниження тимчасової жорсткості та видалення залишкового хлору. Водний екстракт чаю готували настоюванням листя чаю за температури $95-100{ }^{\circ} \mathrm{C}$ протягом 10-15 хв.

Водні екстракти пряно-ароматичних і лікарських рослин приготовано так: подрібнену сировину залито гарячою водою $\left(\mathrm{t}=95^{\circ} \mathrm{C}\right)$, витримано протягом 10-30 хв, пропущено через фільтр, охолоджено до температури $25-27^{\circ} \mathrm{C}$ та в розрахунковій кількості внесено до сусла на початку бродіння. 


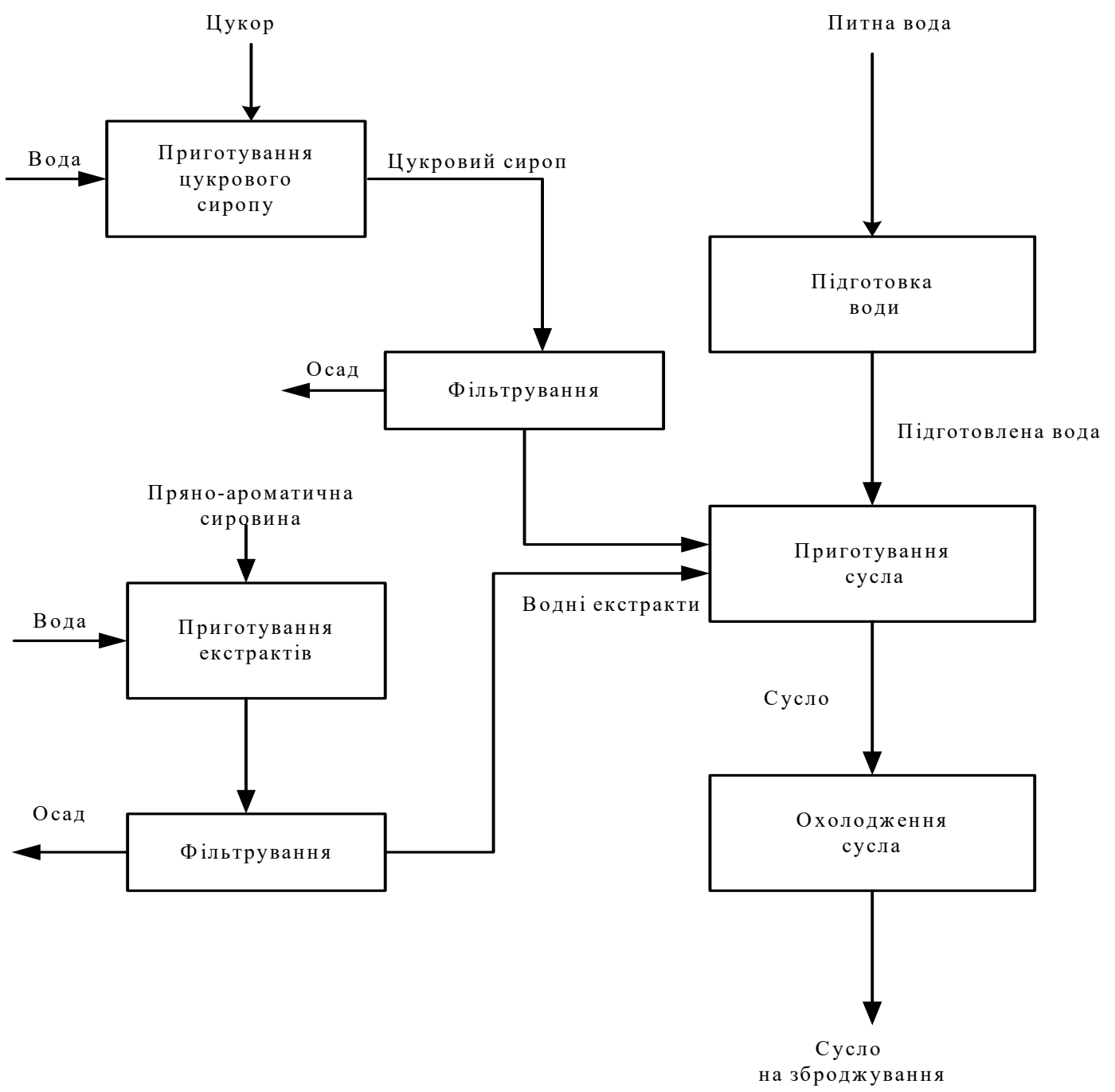

Принципова технологічна схема приготування сусла для зброджування культурою Medusomyces gisevii $V$

Вміст сухих речовин, кислотність сусла та органолептичні показники готових напоїв визначено за ДСТУ 4069:2016 [19]. Сусло зброджено до зниження вмісту сухих речовин на 1.0-1.5\% або досягнення титрованої кислотності до 2.5-3.5 $\mathrm{cm}^{3} \mathrm{NaOH}$ концентрацією 1 моль/дм ${ }^{3}$ на $100 \mathrm{~cm}^{3}$ сусла. Органолептичні показники готових ферментованих напоїв оцінено за 19-баловою шкалою (колір і зовнішній вигляд максимум 7 балів, смак і аромат - максимум 12 балів) [20].

Результати дослідження. Головними критеріями при виборі ПАС були хімічний склад, фізіологічна дія, доступність і сумісність при одночасному використанні. При цьому враховано, щоб обрані рослини мали оригінальні органолептичні властивості та були поширені на території України.

М'ята периева (м'ята холодна) - багаторічна запашна трав'яниста рослина. До хімічного складу входять, \%: ефірні олії - 5.3; органічні кислоти (зокрема, урсолова -0.3 , хлорогенова -0.12 , олеїнова -0.8 , 
лінолева -0.5 , нікотинова -0.2$)$; таніди $-5-12$. Хлорогенова кислота сприяє ефективному розщепленню жирів, підсилює їх утилізацію до 47 \%, регулює рівень цукру в крові. Урсолова кислота має протипухлинні та антиканцерогенні властивості, олеїнова позитивно впливає на підтримання імунітету, сповільнює розвиток хвороб серця і сприяє виробленню антиоксидантів [8;21]. До хімічного складу м'яти входять також вітаміни Р (рутин) і К (філохінон). Перший не виробляється організмом людини, $\epsilon$ синергістом вітаміну С, сприяє підвищенню міцності капілярів, нормалізації стану при прискореному серцевому ритмі та кров'яному тиску, а також бере участь в утворенні колагену. Вітамін К регулює механізм згортання крові, задіяний у синтезі білка, відновленні та формуванні кісткових тканин організму, роботі нирок, проходженні окисно-відновних процесів і має антибактеріальну дію [8].

Меліса (медова трава, лимонна трава) містить, \%: ефірну олію 0.05-0.35 з лимонним ароматом (цитраль, гераніол, мірцен та ін.); каротину -0.007-0.01; дубильних речовин - до 5.0 та органічні кислоти (кавову, олеанолову, урсолову та ін.) [21]. Ефірна олія меліси має седативну й бактерицидну дію, використовується при захворюваннях серцево-судинної і нервової систем, при застудах.

Лофант (лофант анісовий, багатоколосник фенхельний) під час цвітіння накопичує більше ніж $1.5 \%$ ефірної олії із $70 \%$-м вмістом метилхавіколу, що надає рослині анісового аромату [8]. Має антивірусну та антимікробну дію. Настої лофанту використовують при нервових збудженнях, вегето-судинній дистонії, перепадах кров'яного тиску внаслідок емоційних збуджень.

Солодковий корінь (корінь солодки голої) містить, \% - цукри: 0.6-15.2 - глюкози, 0.3-20.3 - фруктози, 0.1-0.6 - мальтози; полісахариди: до 34.0 - крохмалю, до 30.0 - целюлози; органічні кислоти: 4.0-4.6 лимонну, яблучну, янтарну, фумарову; ефірну олію $-8.3-14.2$; дубильні речовини тощо [21]. Застосовується у вигляді сиропів та екстрактів як замінник цукру в безалкогольних напоях і пиві, має піноутворювальні властивості. В медицині використовується як протизапальний та антигістамінний засіб [8].

Внесення зазначених інгредієнтів можливе як на стадії приготування сусла, так і при купажуванні збродженого напою. Для досягнення максимальної оздоровчої дії та кращих органолептичних характеристик готового напою за рахунок синергетичного ефекту взаємодії інгредієнтів доцільним можна вважати їх внесення до сусла на початку бродіння. Пряно-ароматичну сировину додавали у вигляді водних екстрактів до сусла в раціональній кількості, достатній для профілактичних і оздоровчих цілей, $-0.05-0.50$ г на 1 дм³ сусла [21]. Деякі рослини - зокрема меліса, лофант, корінь солодки - містять значну кількість цукрів, флавоноїдів та інших речовин, які надають напою солодкий смак. Саме тому в зразках № 12, 18 і 23 відповідно зменшено кількість цукру, і початковий вміст сухих речовин становив $5 \%$. Рецептури напоїв і результати досліджень наведено в таблииі. 


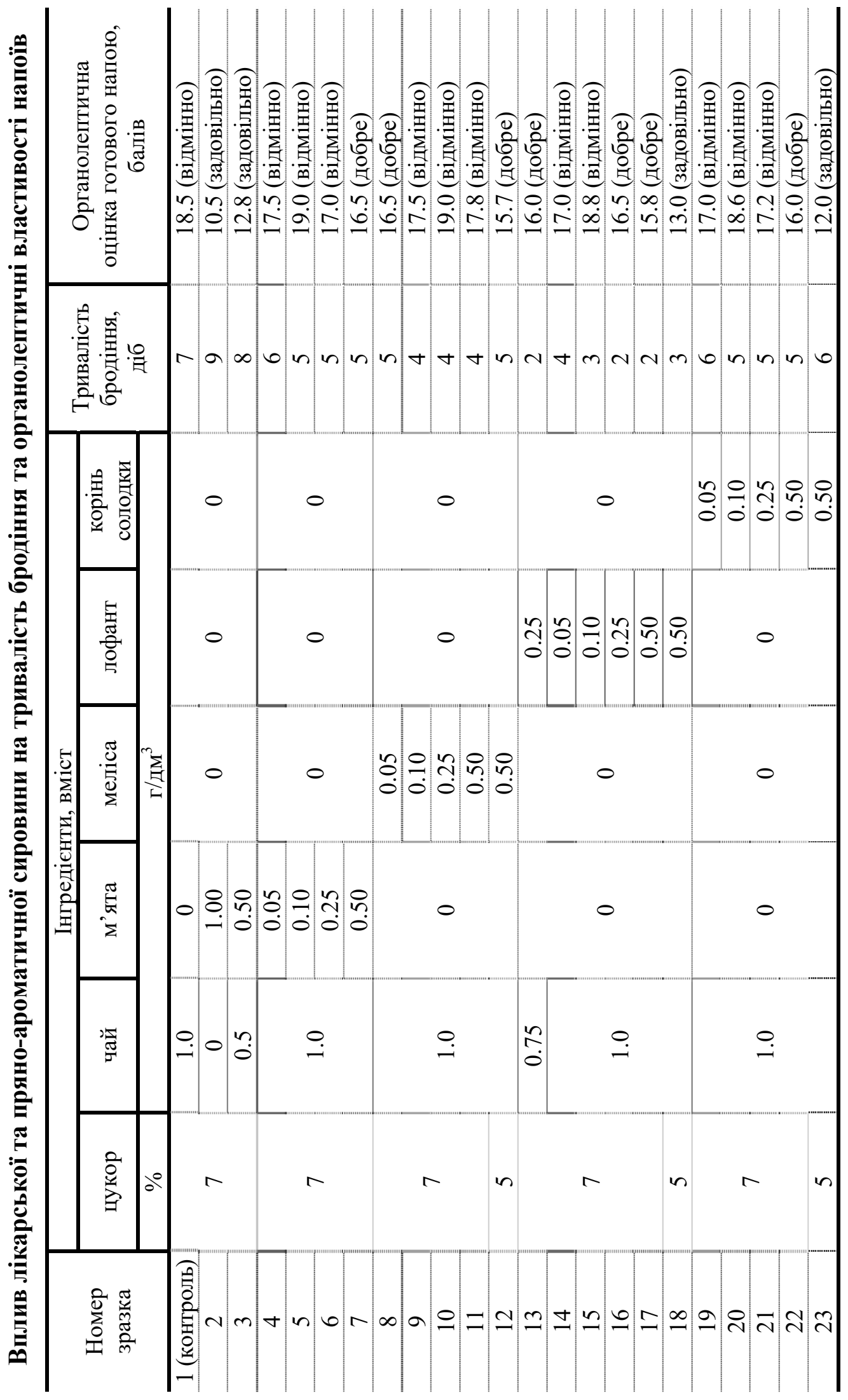


Найвищі оцінки з органолептичних показників мали напої зразків № $1,5,10,15,20$, в яких вдало підібрана рецептура i, можна вважати, додано раціональну кількість ПАС.

Зниження вмісту цукру до $5 \%$ у зразках № 12, 18, 23 виявилося недоцільним, як і зменшення на 25-50 \% кількості чаю в зразках № 3 і 13, про що свідчить їх невисока органолептична оцінка.

Внесення рослинної сировини на початку бродіння завдяки збагаченню сусла поживними речовинами привело до скорочення тривалості бродіння - 3 7-ми до 5-ти днів при використанні м'яти й солодки та до 4-х і 3-х днів - меліси та лофанту відповідно.

Висновки. Дослідженням доведено можливість розширення асортименту напоїв на основі культури Medusomyces gisevii $V$ шляхом використання пряно-ароматичної сировини, яка збагачує напої корисними біологічно активними речовинами.

Обгрунтовано доцільність внесення ПАС на стадії приготування сусла, при цьому тривалість бродіння скорочується 37 до 3-5 діб.

Визначено раціональну кількість ПАС при готуванні ферментованих напоїв, зокрема листя м'яти, меліси, лофанту та кореню солодки.

Перспективою подальших досліджень $є$ розширення асортименту ферментованих напоїв на основі Medusomyces gisevii $V$ з використанням іншої пряно-ароматичної та лікарської рослинної сировини.

\section{СПИСОК ВИКОРИСТАНИХ ДЖЕРЕА}

1. Прибильський В. Л., Романова 3. М., Сидор В. М., Цед О. О. та ін. Технологія безалкогольних напоїв : підруч. ; за ред. докт. техн. наук., проф. В. Л. Прибильського. Київ : НУХТ, 2014. 310 с.

2. Даниелян Л. Т. Чайный гриб (Kombucha) и его биологические особенности. М. : ОАО Изд-во "Медицина", 2005. 176 с.

3. Карпутіна М. В., Харгелія Д. Д. Нешкідливі технології у виробництві безалкогольних напоїв з натуральної рослинної сировини. Наукові пр. НУХТ. 2016. T. 22, № 6. C. 220-227.

4. Zhumabekova K., Zhumabekova B., Mamonova L., Rymzhanova Z., Tarasovskaya N. Effect of herbal supplements on antimicrobial activity of Kombucha tea. Proceedings of the Malaysia International Symposium "Sustainable Bioresources for Bioeconomy". Malaysia. 2014. 58 p.

5. Gunther W. Frank. Kombucha. Healthy beverage and natural remedy from the Far East. Publ. H. Ennsthaler. F-4402 Steyr. 1995. 160 p.

6. Добоний И. В., Билько М. В., Кораблева О. А. Научный подход к составлению композиций из пряно-ароматического сырья для вермутов. Пищевая пром-сть: наука и технологии. Минск. 2012. С. 17-19.

7. Іванова В. Безалкогольні напої на основі фітоекстрактів. Міжнар. наук.практ. журн. "Товари і ринки". 2011. № 2 (12). С. 69-74.

8. Вітряк О. П. Технологічні аспекти використання пряно-ароматичної сировини у технології напоїв. Проблеми екологічної біотехнології. 2014. № 2. C. 14-21. URL : http://ecobio.nau.edu.ua/index.php/ecobiotech/article/view/7463. 
9. Романова 3. М., Романов М. М. Перспективи використання рослинної сировини у пивоварінні. Проблеми екологічної біотехнології. 2012. № 2. URL : http://ecobio.nau.edu.ua/index.php/ecobiotech/article/view/3032/2967.

10. Патент 2210952 С2 РФ МПК, А 23 L 2/00, А 23 L 2/38, A 23 L 2/52, A 23 L 2/58. Безалкогольный напиток "Мелиссовый". Огарков Б. Н., Огаркова Г. Р., Самусенок Л. В., Алексеева Т. Н., Орещенко А. В. № 2000122469А ; заявл. 25.08.2000 ; опубл. 20.09.2002 ; RU2210952C2 ; опубл. 27.08.2003.

11. Жумабекова Б. К., Жумабекова К. А. Технология получения чайного кваса с добавлением экстракта душицы. Фундаментальные исследования. 2015. № 2 (11). С. 2370-2373.

12. Патент 29795 України, МКИ6 А 23 L 2/00, С 12 С 3/00. Асоціація мікроорганізмів Medusomyces gisevii $V$ для одержання безалкогольних напоїв бродіння. Прибильський В. Л., Домарецький В. А., Вітряк О. П. № 97063367 ; заявл. 27.06.1997 ; опубл. 29.12.1999, Бюл. № 8 ; 15.11.2000, Бюл. № 6-II.

13. ДСанПіН 2.2.4-171-10. Гігієнічні вимоги до води питної, призначеної для споживання людиною. Київ : МОЗ України, 2010. 36 с.

14. ДСТУ 7525:2014. Вода питна. Вимоги до контролювання якості. Київ : Мінекономрозвитку України, 2014. 25 с.

15. ДСТУ 4623:2006/ГОСТ 31361-2008. Цукор білий. Технічні умови. Київ : ДП "УкрНДНЦ", 2007. 18 с.

16. ДСТУ 7174:2010. Чай чорний байховий фасований. Технічні умови. Київ : Держспоживстандарт, 2011. 18 с.

17. Державна Фармакопея України. 2-ге вид., доп. 2. Харків : Держ. підприємство "Укр. наук. фармакопейний центр якості лікарських засобів". 2018. 336 с.

18. ГОСТ 22839-88. Корни и корневища солодки. Технические условия. М. : Гос. агропром. ком. СССР, 1988. 17 с.

19. ДСТУ 4069:2016. Напої безалкогольні. Загальні технічні вимоги. Київ : ДП "УкрНДНЦ", 2016. 22 с.

20. ТИ 10-04-06-144-87. Технологическая инструкция по производству безалкогольных напитков и кваса. М. : Гос. агропром. ком. СССР, 1988. Ч. І и II. 295 с.

21. Лікарські рослини. Енциклопедичний довідник ; за ред. А. М. Гродзінського. Київ : Укр. енциклопедія. 1992. 544 с.

Стаття надійшла до редакиії 05.06.2018.

Vitriak O., Tkachenko L., Prybylskyi V. The fermented beverages technology based on Medusomyces gisevii $V$ with spicy and aromatic herbs.

Background. Fermented beverages are natural products that can improve the functioning of human body systems and functions. The using of spices and aromatic herbs (SAH) that grow in Ukraine, to improve the functional and organoleptic characteristics of the finished product is relevant.

The aim of the study is substantiate the usage of SAH for the fermented beverages technology based on Medusomyces gisevii $V$ to intensify technological process and improve organoleptic characteristics.

Material and methods. A culture of the tea mushroom Medusomyces gisevii $V$ was used in the research. The wort for fermentation was prepared from drinking water, sugar syrup and black tea. At the stage of fermentation we added aqueous extracts: peppermint, lemon melissa, licorice root and lofant anise. The 
organoleptic characteristics of the beverages and the duration of fermentation were determined. The decrease of dry substances content by $1-1.5 \%$ or getting the acidity to $2.5-3.5 \mathrm{~cm}^{3} \mathrm{NaON}$ with concentration $1 \mathrm{~mol} / \mathrm{dm}^{3}$ per $100 \mathrm{~cm}^{3}$ of the beverage was considered a criteria of fermentation finishing.

Results. SAH in the form of aqueous extracts was added to the wort before fermentation. It was found, that samples of beverages, which got the highest organoleptic assessment, contain $7 \%$ sugar, tea $1 \mathrm{~g} / \mathrm{dm}^{3}$, and quantity of mint leaves, melissa, lofant, licorice root, respectively, $0.1 ; 0.25 ; 0.1 ; 0.1 \mathrm{~g}$ per $1 \mathrm{dm}^{3}$ of the wort.

Conclusion. The possibility of expanding the range of beverages based with the culture of Medusomyces gisevii $V$ by using SAH is proved.

The introduction of SAH on the stage of the wort preparation was substantiated. It reduces the duration of its fermentation from 7 to 3-5 days.

The rational quantity of SAH, such as mint, melissa, lofant and licorice root, is determined.

Keywords: fermented beverages, culture of microorganisms Medusomyces gisevii $V$, spicy and aromatic herbs.

\section{REFERENCES}

1. Prybyl's'kyj V. L., Romanova Z. M., Sydor V. M., Ced O. O. ta in. Tehnologija bezalkogol'nyh napoi'v : pidruch. ; za red. dokt. tehn. nauk., prof. V. L. Prybyl's'kogo. Kyi'v : NUHT, 2014. $310 \mathrm{~s}$.

2. Danieljan L. T. Chajnyj grib (Kombucha) i ego biologicheskie osobennosti. M. : OAO Izd-vo "Medicina", 2005. $176 \mathrm{~s}$.

3. Karputina M. V., Hargelija D. D. Neshkidlyvi tehnologii' u vyrobnyctvi bezalkogol'nyh napoi'v z natural'noi' roslynnoi' syrovyny. Naukovi pr. NUHT. 2016. T. 22, № 6. S. 220-227.

4. Zhumabekova K., Zhumabekova B., Mamonova L., Rymzhanova Z., Tarasovskaya N. Effect of herbal supplements on antimicrobial activity of Kombucha tea. Proceedings of the Malaysia International Symposium "Sustainable Bioresources for Bioeconomy". Malaysia. 2014. 58 p.

5. Gunther $W$. Frank. Kombucha. Healthy beverage and natural remedy from the Far East. Publ. H. Ennsthaler. F-4402 Steyr. 1995. 160 p.

6. Dobonij I. V., Bil'ko M. V., Korableva O. A. Nauchnyj podhod k sostavleniju kompozicij iz prjano-aromaticheskogo syr'ja dlja vermutov. Pishhevaja prom-st': nauka i tehnologii. Minsk. 2012. S. 17-19.

7. Ivanova . Bezalkogol'ni napoi' na osnovi fitoekstraktiv. Mizhnar. nauk.-prakt. zhurn. "Tovary i rynky". 2011. № 2 (12). S. 69-74.

8. Vitrjak $O . P$. Tehnologichni aspekty vykorystannja prjano-aromatychnoi' syrovyny u tehnologii' napoi'v. Problemy ekologichnoi' biotehnologii'. 2014. № 2. S. 14-21. URL : http://ecobio.nau.edu.ua/index.php/ecobiotech/article/view/7463.

9. Romanova Z. M., Romanov M. M. Perspektyvy vykorystannja roslynnoi' syrovyny u pyvovarinni. Problemy ekologichnoi' biotehnologii'. 2012. № 2. URL : http://ecobio.nau.edu.ua/index.php/ecobiotech/article/view/3032/2967.

10. Patent 2210952 S2 RF MPK, A 23 L 2/00, A 23 L 2/38, A 23 L 2/52, A 23 L 2/58. Bezalkogol'nyj napitok "Melissovyj". Ogarkov B. N., Ogarkova G. R., Samusenok L. V., Alekseeva T. N., Oreshhenko A. V. № 2000122469A ; zajavl. 25.08.2000 ; opubl. 20.09.2002; RU2210952C2 ; opubl. 27.08.2003.

11. Zhumabekova B. K., Zhumabekova K. A. Tehnologija poluchenija chajnogo kvasa s dobavleniem jekstrakta dushicy. Fundamental'nye issledovanija. 2015. № 2 (11). S. 2370-2373. 
12. Patent 29795 Ukrai'ny, MKY6 A 23 L 2/00, S 12 S 3/00. Asociacija mikroorganizmiv Medusomyces gisevii V dlja oderzhannja bezalkogol'nyh napoi'v brodinnja. Prybyl's'kyj V. L., Domarec'kyj V. A., Vitrjak O. P. № 97063367 ; zajavl. 27.06.1997 ; opubl. 29.12.1999, Bjul. № $8 ; 15.11 .2000$, Bjul. № 6-II.

13. DSanPiN 2.2.4-171-10. Gigijenichni vymogy do vody pytnoi', pryznachenoi' dlja spozhyvannja ljudynoju. Kyi'v : MOZ Ukrai'ny, 2010. $36 \mathrm{~s}$.

14. DSTU 7525:2014. Voda pytna. Vymogy do kontroljuvannja jakosti. Kyi'v : Minekonomrozvytku Ukrai'ny, 2014. $25 \mathrm{~s}$.

15. DSTU 4623:2006/GOST 31361-2008. Cukor bilyj. Tehnichni umovy. Kyi'v : DP "UkrNDNC", 2007. $18 \mathrm{~s}$.

16. DSTU 7174:2010. Chaj chornyj bajhovyj fasovanyj. Tehnichni umovy. Kyi'v : Derzhspozhyvstandart, 2011. $18 \mathrm{~s}$.

17. Derzhavna Farmakopeja Ukrai'ny. 2-ge vyd.. dop. 2. Harkiv : Derzh. pidpryjemstvo "Ukr. nauk. farmakopejnyj centr jakosti likars'kyh zasobiv". 2018. $336 \mathrm{~s}$.

18. GOST 22839-88. Korni i kornevishha solodki. Tehnicheskie uslovija. M. : Gos. agroprom. kom. SSSR, 1988. $17 \mathrm{~s}$.

19. DSTU 4069:2016. Napoi' bezalkogol'ni. Zagal'ni tehnichni vymogy. Kyi'v : DP "UkrNDNC", 2016. $22 \mathrm{~s}$.

20. TI 10-04-06-144-87. Tehnologicheskaja instrukcija po proizvodstvu bezalkogol'nyh napitkov i kvasa. M. : Gos. agroprom. kom. SSSR, 1988. Ch. I i II. 295 s.

21. Likars'ki roslyny. Encyklopedychnyj dovidnyk ; za red. A. M. Grodzins'kogo. Kyi'v : Ukr. encyklopedija. 1992. 544 s. 